This is the author's final, peer-reviewed manuscript as accepted for publication. The publisher-formatted version may be available through the publisher's web site or your institution's library.

\title{
Challenges Involved in the Salmonella Saintpaul Outbreak and Lessons Learned
}

Ethel Taylor, Justin Kastner, David Renter

\section{How to cite this manuscript (APA format)}

If you make reference to this version of the manuscript, use the following citation format:

Taylor E, Kastner J, Renter D. (2009). Challenges involved in the Salmonella Saintpaul outbreak and lessons learned. Retrieved from http://krex.k-state.edu

\section{Published Version Information}

Citation: Taylor E, Kastner J, Renter D. (2009). Challenges involved in the Salmonella Saintpaul outbreak and lessons learned. Journal of Public Health and Management Practice, 16(3):221-231.

Copyright: Copyright 2010 Wolters Kluwer Health | Lippincott Williams \& Wilkins

Digital Object Identifier (DOI): doi: 10.1097/PHH.0b013e3181ca650d

\section{Publisher's Link:}

http://journals.Iww.com/jphmp/Abstract/2010/05000/Lessons_Learned_From_the_Invest igation_of_a.3.aspx

This item was retrieved from the K-State Research Exchange (K-REx), the institutional repository of Kansas State University. K-REx is available at http://krex.k-state.edu 


\title{
Challenges involved in the Salmonella Saintpaul outbreak and lessons learned
}

\author{
Authors: \\ Ethel Taylor, DVM, MPH \\ Research Veterinary Fellow (affiliated with the Midwest Regional Center of Excellence in \\ Biodefense and Emerging Infectious Diseases) \\ Department of Diagnostic Medicine/Pathobiology \\ 308 Coles Hall \\ Kansas State University \\ Manhattan, Kansas 66506
}

Justin Kastner, PhD (author for correspondence; jkastner@k-state.edu; 785-532-4820)

Assistant Professor, Food Safety and Security

Co-director, Frontier program for the historical studies of border security, food security, and trade policy

Department of Diagnostic Medicine/Pathobiology

310 Coles Hall

Kansas State University

Manhattan, Kansas 66506

David Renter, DVM, PhD

Assistant Professor, Veterinary Epidemiology

Department of Diagnostic Medicine/Pathobiology

307 Coles Hall

Kansas State University

Manhattan, Kansas 66506

The authors thank Dr. Andrew Maccabe, Centers for Disease Control and Prevention, for his assistance. 


\begin{abstract}
A 2008 multistate foodborne outbreak of Salmonella Saintpaul caused more than 1,400 illnesses in the United States (U.S.). Although initial investigations suggested tomatoes as the potential vehicle, jalapeño and serrano peppers were subsequently found positive for the outbreak strain. The uncertainty associated with this incident caused government, industry, and the public to question the efficacy of the U.S. food safety system. Examination of the response to this incident exposed breakdowns in several areas. Communication at all levels was lacking, leading to an absence of coordinated actions and conflicting risk communication messages. Variations in resources between local and state health departments created delays in gathering accurate information for epidemiological investigations. Although new laws required increased documentation, rapid and thorough traceback of produce products remained elusive. Three factors contributed to the difficulty in the Salmonella Saintpaul outbreak, including (1) delayed response due to discrepancies in available resources and expertise at state and local levels, (2) inadequate communication between stakeholders and agencies, and (3) poor traceability capabilities. Future responses to foodborne illness outbreaks may be improved by addressing these three factors.
\end{abstract}

Keywords: food safety, produce, outbreak, Salmonella, Salmonella Saintpaul 


\section{Introduction, Research Questions, and Methodology}

On May 22, 2008, the United States (U.S.) Centers for Disease Control and Prevention (CDC) was notified by the New Mexico Department of Health of four people infected with the same strain of Salmonella — an unusual serotype, Salmonella Saintpaul. Three months later, a total of 1,442 cases from 43 states, the District of Columbia and Canada were reported. Meanwhile, consumer confidence in the safety of the food supply waned ${ }^{1}$. This outbreak focused attention on the current system for investigation and regulation of foodborne diseases and illuminated gaps in the U.S. federal government's ability to quickly and accurately trace potentially contaminated food vehicles back to their source. Some people claimed the U.S. food safety system worked as it should and cited the isolation of a matching strain of Salmonella Saintpaul from a jalapeño pepper in Texas and additional positive samples found on the suspected farm of origin in Mexico. However, others felt the current system for multi-state outbreak response and investigation failed and needs to be fixed ${ }^{2}$.

Thought leaders in food safety regulation agreed that the outbreak and subsequent investigation posed a unique level of complexity (and difficulty) rarely witnessed in public health response. However, these same leaders debate the source of the complexity. Some maintain the investigation represents an atypical incident ${ }^{3,4}$ for several reasons. First, most outbreaks involve one food vehicle, whereas at least two food products were contaminated with the outbreak strain of Salmonella Saintpaul in this incident. Also, neither raw jalapeño nor raw serrano peppers had been previously associated with Salmonella contamination, and little information was available regarding growth rates or survival times at the onset of this outbreak ${ }^{8}$. These foods are often used in small quantities as garnishes or combined with other foods and cases might be unaware of consuming these "stealth vehicles." In the outbreak, epidemiologic 
analysis was complicated by the lack of large, identified clusters early in the investigation. In the initial weeks of the outbreak, most "clusters" consisted of 2-3 cases-numbers too small to determine statistical significance between foods consumed in cases versus geographically matched controls, or created marked variations in calculated odds ratios of food items between clusters, leading to some uncertainty in which foods were most likely to be associated with illness ${ }^{10-12}$. A further complication in the statistical analyses was that tomatoes and jalapeño or serrano peppers were often consumed together, creating a strong, collinear relationship that increased the difficulty in determining a numerical value for statistical significance of these foods individually ${ }^{8}$.

While many feel this outbreak was an anomaly, others point to the investigation's cumbersome intricacy as evidence of a fundamentally flawed food safety system ${ }^{2}$. This paper will not, and does not seek to, resolve this disagreement; instead, it seeks to address another question, the answer to which will help inform the debate:

What factors most affected the difficulty experienced during the Salmonella Saintpaul outbreak and subsequent investigation, and are these factors representative of larger problems in the food system?

Data for this paper were gathered from a wide range of stakeholders, including government employees of state and federal public health and food safety agencies, industry and consumer representatives, and state and national legislators (see Table 1). In the wake of this outbreak, Congress summoned principal participants for testimonies before the U.S. House of Representatives Committees on Agriculture (Subcommittee on Horticulture and Organic Agriculture), Energy and Commerce (Subcommittee on Oversight and Investigation), and 
Appropriations (Subcommittee on Agriculture, Rural Development, Food and Drug

Administration and Related Agencies); the bulk of information is drawn from public testimony delivered before these groups. Additional data regarding the outbreak investigation were gathered from CDC and Food and Drug Administration (FDA) bulletins and reports; much of this is summarized in Table 2. Relevant publications from several non-governmental entities were also consulted.

This paper-an exploration of a treasure trove of emerging literature regarding a recent food safety incident — draws on an inductive, yet systematic, research approach. Inductive analysis involves the gathering of data from which observations are extracted. While many view traditional, deductive methods as superior to inductive methods, a number of scholars maintain inductive research is a legitimate approach to numerous problems, particularly in the field of social science ${ }^{5}$. The research presented in this paper relies on methods that are highly inductive in nature; in this inductive analysis, the authors explored the range of literature regarding the Salmonella Saintpaul outbreak and identified specific factors that contributed to the outbreak's complexity. The modern food system is multifaceted and complex, with government, industry, and the public playing significant roles ${ }^{6}$. Therefore, it is good and appropriate to analyze multiple perspectives from these groups in order to formulate ideas which best reflect the concerns and challenges of all stakeholders. Some of these perspectives (e.g., Congressional testimony) represent individual experts' opinions, but the authors accept this limitation in their overall effort to acquire multiple viewpoints. Specifically, through an inductive review of government, industry, and consumer reports (see Table 1) as well as multidisciplinary analyses, this study inductively proposes three factors within the current food safety system that greatly 
contribute to the complexity of foodborne disease outbreaks, as evidenced by the Salmonella Saintpaul investigation. These three factors form the framework in the results section.

\section{Results}

Three factors emerged as the key elements which most increased the complexity of and difficulty experienced during the Salmonella Saintpaul outbreak. These included (1) delayed response due to discrepancies in resources and expertise at state and local levels, (2) inadequate communication between stakeholders and agencies, and (3) poor traceability capabilities.

\section{Factor 1: Delayed response due to variability in resources and expertise at state and local levels}

In a typical foodborne illness outbreak, clusters of cases are identified by local or state public health departments, which may solicit aid from the CDC in the form of Epi-Aid teams, usually consisting of epidemiologists, public health specialists, and Epidemic Intelligence Service (EIS) officers. The primary role of the CDC, which often relies on data provided by state and local personnel, is to identify potential food vehicles of infection in order to prevent further illnesses. Once a food item has been implicated (either through epidemiological or microbiological evidence), the FDA or the U.S. Department of Agriculture (USDA) is notified in order to pursue further investigation and possible regulatory action. Once the regulatory agency (USDA or FDA) has been notified, tracing the food back to the source of contamination begins. Historically, the FDA has relied on voluntary product recalls from companies, while the USDA has enjoyed more authority to recall contaminated products.

The current food safety system relies on coordinated efforts between local, state, and federal agencies with opportunities for discrepancies in speed of response at several levels. The 
speed of involvement of the CDC is highly dependent on how quickly the local or state government decides additional assistance is needed and submits a request for the same. There is great variability in available resources and expertise at state and local levels, which can influence both the speed with which local officials are able to respond to potential cases and request federal assistance. The success of national surveillance systems is highly dependent on the effectiveness of state and local public health systems ${ }^{14}$; therefore, the availability of resources at the state and local level can greatly influence the responsiveness of the federal government to potential outbreak situations. According to the Council to Improve Foodborne Outbreak Response (CIFOR), the Salmonella Saintpaul outbreak highlighted serious deficiencies in the current foodborne disease surveillance system and initial epidemiological investigations ${ }^{15}$. Since CDC involvement is dependent on invitations from states, actual CDC support may be delayed. In the Salmonella Saintpaul investigation, the CDC was not formally invited to step into a coordinating role until June 3 (see Table 2). CDC personnel were not deployed into the field to actively participate in data collection until June 18. The inability of the CDC to act independently without the invitation of states limits the amount of federal resources applied towards epidemiological investigations.

While some state and local public health departments are well-funded and able to carry out foodborne disease outbreak investigations quickly and efficiently, many others lack adequate resources which can negatively impact investigations in several ways. The advent of PulseNet, a centralized databank of PFGE patterns for six foodborne pathogens of interest, including Campylobacter, Salmonella, and Escherichia coli O157:H7, has markedly increased the surveillance capabilities of the public health system. In 2005, public health laboratories uploaded more than 30,000 Salmonella patterns, resulting in the recognition of 152 multistate 
Salmonella clusters ${ }^{15}$. The Minnesota Department of Public Health, recognized as one of the premiere public health agencies in the nation, has the ability to characterize and enter isolates into PulseNet within 3 days. In the outbreak of Salmonella Saintpaul, however, the nationwide median time from onset of illness until PFGE pattern was entered into PulseNet was 17 days, with some states taking more than 27 days ${ }^{8}$. These delays may be due to multiple causes, including substantial backlogs of samples, insufficient personnel, and inadequate laboratory equipment. Indeed, many state and local laboratories lack the necessary equipment for "realtime" testing, leading to significant delays between onset of illness and identification of a pathogen ${ }^{14,15}$. In the Salmonella Saintpaul outbreak, Texas experienced a critical delay in identification of cases, which led to several restaurant-associated clusters (necessary for casecontrol studies) going unrecognized for a prolonged period.

Shortages in state and local resources and expertise were magnified by the fact that Salmonella Saintpaul is a relatively rare serotype with an estimated annual occurrence of 400 cases per year across the U.S. compared to serotypes such as $S$. Typhimurium or $S$. Enteritidis, which normally cause more than 1,000 cases per year ${ }^{4,13}$. Many laboratories may not have the supplies and reagents available to test these more uncommon serotypes. Federal agencies will continue to struggle to identify contaminated food products unless all state and local public health laboratories are brought up to minimum standards. This has led to requests for funding by A.G. Kawamura, Secretary of the California Department of Food and Agriculture, to implement a uniform system for reporting and investigations of outbreaks in all states ${ }^{7}$. In July 2008 , then Senator Barack Obama proposed a bill to increase state and local resources for surveillance and investigation activities by $\$ 25,000,000$ a year for three years. While these are steps in the right 
direction, more needs to be done to promote capacity building for the investigation, control, and prevention of foodborne disease ${ }^{19}$.

\section{Factor 2: Inadequate Communication Between Agencies and Stakeholders}

A key concern in any epidemiological investigation, and one that has come under close scrutiny in this outbreak, is establishing and maintaining communication among governmental agencies and various stakeholders in order to quickly and efficiently trace food vehicles back to the source of contamination and remove affected products from the marketplace to prevent further illnesses. Both the FDA and the CDC have come under heavy fire from government and industry leaders for their perceived failure to communicate both with each other and with the tomato industry ${ }^{18}$.

In order to accomplish these goals, the CDC works closely with state public health authorities to identify outbreaks, determine common exposures, and ascertain the potential number of individuals affected or at risk. In states with highly autonomous local health departments, information sharing through the state to the CDC may not occur. Currently, in 50 states there are more than 3,000 local health departments ${ }^{16}$. In some states, such as Minnesota, the public health system is highly centralized with decision making authority lying with the state, whereas many other states are highly decentralized with the local public health officials holding more authority than the state in regards to cases in their area. In approximately $50 \%$ of states, local public health officials are responsible for conducting case interviews for foodborne disease, in addition to a myriad of other duties and issues - including, but not limited to, programs for immunizations, sexually transmitted diseases, and birth defects ${ }^{15}$. In these areas, interviews of cases to determine potential food vehicles may not occur for several weeks after the illness, 
leading to the possibility of inaccuracies in recall and obscuring of epidemiological relationships 17. Unreasonably long delays in receiving information from potential cases, as well as complications arising from differing questionnaires administered by multiple individuals within a single outbreak or area, may also occur ${ }^{2}$. Since the CDC has relationships predominantly with states, local agencies conducting the actual investigations are often unable to easily access the valuable resources the CDC can provide.

While the FDA also collects epidemiologic information during a foodborne outbreak, its priority is to trace the implicated food vehicle back to the source, determine contributing factors leading to the contamination, and work with regulated industries to minimize the likelihood of similar circumstances recurring in the future. FDA has the responsibility to take regulatory action to prevent more contaminated foodstuffs from entering the food supply through voluntary recalls, and to collect evidence that may be used to pursue punitive measures. Since information they collect may be used in legal action against individuals or organizations, it must be able to meet high evidentiary standards. This greatly curtails the FDA's ability to solicit information or expert opinions from individuals in industry, whose companies might or might not become involved as the investigation progresses. Additionally, the FDA is very limited in the amount of information they can share with outside groups due to federal regulations regarding "trade secrets" and other proprietary information ${ }^{16}$. In the case of Salmonella Saintpaul, this led to much dissatisfaction on the part of the tomato industry, whose members felt excluded from offering vital information which would have absolved U.S. tomatoes as the source of contamination — and potentially saved the U.S. tomato industry millions of dollars in lost revenue 20. Similarly, the FDA also has been criticized for restricting the amount of information it shares with state officials, limiting the effectiveness of aid provided by the states. In particular, state 
officials in Florida, one of the states most affected by the FDA consumer advisory regarding Roma and red round tomatoes, felt that FDA should have requested information from states regarding the stage of production of their tomato growers, thereby allowing the FDA to eliminate most states in a timely fashion instead of the broad consumer advisory which was kept in place until July $17,2008^{18}$.

Several industry stakeholders who were impacted by the Salmonella Saintpaul investigation recommend that measures be taken to foster communication between industry and federal agencies, particularly the FDA ${ }^{20-22}$. Reginald Brown, Executive Vice President of the Florida Tomato Exchange, called for the creation of standing "consulting committees," which could be integrated into the management of future outbreaks ${ }^{20}$. The creation of communication channels with established experts in both industry and academic circles would provide a level of expertise in commodities that the FDA, under current budget limitations, frankly cannot afford. Others have proposed similar mechanisms to facilitate information sharing ${ }^{2,23}$. While Mr. Brown acknowledges concerns on the part of the FDA in regards to confidentiality and conflict of interest on the part of industry committee members, he has not offered specific solutions for this dilemma ${ }^{20}$.

In addition to a lack of communication among other groups, information sharing between FDA and CDC was slow, particularly at the beginning of the outbreak. A frustration from the perspective of state personnel was the lack of uniformity in messages coming from the federal agencies, specifically the reluctance of the FDA to share information as completely as did the $\mathrm{CDC}^{18}$. This disparity reflects a need of the FDA and CDC to coordinate and collaborate on the information released to partner agencies in order that all participants are equally informed, and messaging is consistent and comprehensive. However, in the midst of much criticism, one 
benefit did arise from the protracted Salmonella Saintpaul outbreak. For the first time in recent history, CDC sent several epidemiologists to work with the FDA on the epidemiologic investigation for product traceback. This partnership allowed exchanges of information and ideas, and may serve as a collaborative model for future foodborne disease outbreak response.

Currently, the U.S. food safety system is guided by 35 individual food safety laws, overseen by 14 separate federal entities. This fractured authority among multiple agencies has been blamed by many as the underlying problem within the current system ${ }^{2}$. In order to facilitate better communication among federal agencies in regards to foodborne illnesses, both Senator Richard Durbin and Representative Rosa DeLauro have introduced Congressional bills to combine FDA and CDC into a single agency under the Department of Health and Human Services (HHS). In the wake of the Salmonella Saintpaul outbreak and subsequent accusations of poor coordination and communication between agencies, Congresswoman DeLauro has announced plans to again sponsor legislation that would call for a reorganization of the FDA into a Food Safety Administration and a Federal Drug and Device Administration, both within HHS. Response to such large scale reordering of the food safety system has been mixed, with concerns on many sides. However, according to one former USDA Food Safety and Inspection Service administrator, Professor Mike Taylor of Georgetown University, "Over the long run, [such] unification under a modern statutory mandate is the only way to make cost-effective use of the resources the federal government invests in food safety."17

Communication of risks to the American public also needs to be improved, according to representatives from several groups including the National Restaurant Association, Western Growers, and the Center for Science in the Public Interest ${ }^{1,21,24}$. The World Health Organization defines risk communication as "an interactive process of exchange of information 
and opinion among individuals, groups and institutions. ${ }^{25}$. This exchange of information should lead to appropriate behavioral changes by American consumers. A unified voice, displaying a considered assessment of risk and communication of accurate facts, is key to successful communications during a public health emergency ${ }^{26}$. A study to develop recommendations for effective risk communication in regards to foodborne illnesses has been proposed ${ }^{2}$; guidelines for effective communication are available from several international agencies ${ }^{27,28}$. More attention to appropriate risk communication on the part of the government should boost the frequency of desirable responses on the part of the American public as well as increase the spirit of cooperation between government and industry.

\section{Factor 3: Poor Traceability Capabilities}

In any epidemiological investigation, the ability to quickly and accurately trace a product back to its source is crucial to successful isolation of the pathogen. The Public Health Security and Bioterrorism Preparedness and Response Act of 2002 (Bioterrorism Act) mandated new traceback requirements; however, during the Salmonella Saintpaul investigation, the FDA encountered significant difficulties in the traceback of tomatoes. A report conducted by HHS's Office of Inspector General found similar problems, with only 5 of 40 food products successfully traced throughout the entire chain of distribution. Reasons cited for this lack of traceability included lack of lot-specific labeling and mixing of products from multiple sources. In addition, $25 \%$ of facilities involved were unaware of recordkeeping requirements ${ }^{29}$. This highlights the need for better traceability systems in produce ${ }^{30-32}$.

Several common practices in the tomato industry exacerbate the traceability problem. Tomatoes are routinely packed and repacked at several stages of production to assure uniformity 
of the product and are often sold individually; this commingling makes it difficult to trace the product all the way back to the farm of origin (while dramatically increasing the number of items that might potentially come into contact with the suspected pathogen $)^{3}$. Another problem encountered by the FDA arose from the diversity of records received. At different stages of production, terminology for tomatoes may differ so that tomatoes listed as "hothouse" tomatoes by one party may be termed "tomato bulk" on the next bill of lading. The changes in nomenclature for produce at different steps in the supply chain, as well as the lack of consistently recorded information, increased the time required to follow the implicated tomatoes through distribution channels. In addition, tomatoes are perishable commodities, so by the time an illness was reported, the suspected item was no longer available for testing and similar items from the same location had also exited the food chain. This prevented testing of the implicated products for possible contamination and is a reasonable explanation for the inability to isolate the outbreak strain from tomatoes.

In the wake of the Salmonella Saintpaul outbreak, several in the tomato industry have called for comprehensive traceability standards for all parties involved in growing and marketing tomatoes $^{20,32}$. Based on the high risk of contamination, many groups within the tomato industry have been proactive in creating guidelines for Good Agricultural Practices specifically for tomatoes (T-GAPs), and instituting rapid, complete traceback systems. A number of businesses are able to trace their tomatoes from the distributor back to (a) the field in which they were produced and (b) the crew that harvested them ${ }^{24,31}$. With the use of available software, some vertically integrated companies can use invoice numbers provided by the customer to trace products back within a few minutes, as well as determine where other tomatoes from the source were sent $^{32}$. In mock recall exercises by the California Tomato Farmers organization, 
participants were able to determine the origin of contaminated tomatoes, including location of the field, grower, harvest date, pack date, shipping date and transportation carrier, within 35 minutes ${ }^{31}$. As demonstrated by these examples, rapid traceback of tomatoes is possible with current technology — provided firms are willing to make the investment. According to one California company, these extra costs involved in the safe production of their product are just the price of doing business in today's market ${ }^{32}$. However, when the FDA issued a nationwide consumer advisory, all tomato growers, including those spending large amounts of money to implement rapid traceability programs, were affected. As Dr. James Gorny, Executive Director of Postharvest Technology Research and Information Center at the University of California, Davis stated in regard to the consumer advisory issued by FDA for tomatoes, "It is a huge disincentive for private enterprises to invest in robust food safety programs and traceability systems, if they offer no protection against industry wide shut downs by broad public health advisories. ${ }^{23,}$ During the Salmonella Saintpaul investigation, Florida — the industry leader in the design and implementation of regulations to reduce risk in tomatoes-was the last tomatoproducing area in the U.S. to be cleared by the $\mathrm{FDA}^{20}$ and sustained economic losses estimated at $\$ 100$ million ${ }^{26}$. In order for organizations and states (e.g., Florida) within the tomato industry to benefit from the time and money invested in establishing and adhering to these stringent guidelines, all participants must operate at this high level of record keeping and good agricultural practices.

The 2002 Bioterrorism Act was designed to address many of these concerns; however, based on the recent investigation, there are severe shortcomings in this piece of legislation. While the Bioterrorism Act requires packers, wholesalers, and distributors to keep traceabilityrelated records for all high-risk produce in the supply chain, it does not mandate electronic 
recordkeeping. In addition, one expert has noted that farms, restaurants, and foreign firms are exempted from these recordkeeping requirements ${ }^{33}$. These omissions leave a significant gap in the chain of custody of produce between the farm and the consumer, while the lack of mandatory electronic record keeping creates chaotic amounts of paperwork that must be examined. Another failure in the Bioterrorism Act is that the authority to ensure compliance with recordkeeping standards and to seize records during a foodborne outbreak is not explicitly given to the FDA or any other federal agency ${ }^{33}$. In the recent outbreak, FDA had to wait up to 24 hours for companies to supply the requested information and records were sometimes incomplete. This contributed to the delay in tracing the source of implicated tomatoes, at a time when ten or more people a day might become ill. For firms that fail to comply with the recordkeeping regulations, the FDA can bring only minimal punitive actions, which arguably reduces the incentive to companies to institute and maintain acceptable recordkeeping procedures. The 2002

Bioterrorism Act was crafted with a view to minimize the burden of traceability placed on small producers; however, the projected costs of $\$ 140$ million a year for more stringent requirements ought to be compared to the larger losses recently sustained by the tomato industry, due in large part to poor traceability industry-wide ${ }^{33}$.

Due to concerns with traceability of produce, both industry and government have been attempting to standardize information among all participants. The Produce Marketing Association, in conjunction with Canadian Produce Marketing Association and United Fresh Produce Association, created a Traceability Initiative Steering Committee to establish standards for uniform methods to maintain vital information. These requirements include use of (a) a Global Trade Item Number (GTIN) to identify the manufacturer and type of produce, (b) lot number, and (c) harvest or pack date. This information would be visibly displayed as well as 
encoded into a barcode that could be scanned by each party and electronic records kept by all involved. This initiative relies on key information being maintained throughout the supply chain and the consistent use of electronic records ${ }^{34}$. A recent Associated Press-Ipsos poll reported 86\% of consumers support traceability ${ }^{30}$. This call for better traceability standards industry-wide has been heard by Congress and several bills addressing improved traceability and food safety have been introduced ${ }^{1,35,36,19}$.

Some worry that the costs of raising traceability standards will drive smaller producers out of business; however, the impact of Salmonella Saintpaul on the tomato industry illustrates the price of not having uniform, highly efficient traceability programs in place. Setting mandatory standards for produce traceability across the industry is an important step in the improved protection of the food supply and the prevention of future problems. Improved traceability is one important measure needed to significantly overhaul the food safety system and minimize the risk of foodborne illness ${ }^{30}$.

\section{Discussion}

In the aftermath of the Salmonella Saintpaul outbreak, numerous agencies and individuals have scrutinized each step in the investigation in order to better prepare for future outbreaks in other commodity areas. Close examination of the decisions made and actions taken from multiple points of view demonstrate that foodborne illness outbreaks, and this one in particular, are not simple, black-and-white episodes. In any investigation of this sort, many stakeholders, often with opposing goals or directives, are involved. While everyone agrees that the safety of the public health is paramount, the best way to achieve this goal is often debated. Regardless of 
personal opinions or perspectives, there are many lessons that can be learned from a thorough evaluation of the recent outbreak and investigation.

In retrospect, the most important lesson learned by all parties should be that government cannot continue to function with the current amount of resources; there is a marked need for more funding — especially at state and local levels—-for foodborne surveillance and investigation. This outbreak has revealed that the effectiveness of federal surveillance and outbreak investigations hinge on the ability of the local and state public health systems to rapidly and efficiently identify the causative pathogen and gather information from ill individuals. To do this, many states will need additional resources. The FDA has recently requested applications for the establishment of Food Protection Rapid Response Teams in six states to investigate multistate outbreaks of foodborne illness ${ }^{9}$, but this is insufficient to meet the demands of the entire nation. Each year, the FDA decreases the number of food safety inspections due to budgetary restraints and more money is needed for research to improve pathogen reduction or prevention methods in all food sources. For the FDA alone, the Science Board of Trust for America's Health recommends an increase of $\$ 450$ million dollars over the next five years ${ }^{37}$. To safeguard public health, the U.S. government must make new investments for resource-building activities at local, state, and federal levels.

In addition to increased financial resources, more planning and cooperation needs to take place among involved agencies and other stakeholders during non-crises periods. Many of the problems encountered during the Salmonella Saintpaul outbreak could have been minimized or eliminated by appropriate pre-planning. Memorandums of understanding among FDA, CDC, state public health agencies and state departments of agriculture need to be implemented to establish roles and responsibilities of governmental agencies in response to foodborne illness in 
order to maximize cooperation ${ }^{18}$. Similar agreements are also necessary among states to facilitate sharing of resources, especially in regards to laboratory tools or personnel, in cases where public health capacities of individual states are overwhelmed. The past outbreak has shown the importance of soliciting expertise from outside sources, either academic or industrial. These external committees need to be formed, the roles clearly defined and participants carefully selected before an outbreak occurs in order to be an effective source of information in times of crises. As demonstrated by the Salmonella Saintpaul outbreak, preparation needs to occur before outbreaks take place, not in the midst of them. To effectively use limited resources as wisely as possible, local, state and federal authorities must plan ahead and design ways to work with each other as well as industry and academia to protect the health of the public.

In addition, the federal government needs to reassess the degree of information federal agencies can share with outside experts in order for sufficient information exchange to occur. The FDA, and other federal regulatory agencies, must be able to share information with partners in a timely and comprehensive manner in order to protect the nation's public health ${ }^{16}$.

The highly collinear relationship between tomatoes and jalapeño and serrano peppers (all of which were, at various times, suspected during the Salmonella Saintpaul outbreak) obfuscated statistical associations between these items and illnesses, and posed a special challenge in the investigation. Since the precedent has now been set that "stealth vehicles" can cause large numbers of illnesses, epidemiologists may need to include additional items that are often served together in case-control studies even if there is not a strong statistical association in initial analyses. This outbreak also has illustrated the need for more data-collection and investigationmethods consistency among local and state agencies; establishing universal case questionnaires and uniform reporting requirements for common foodborne pathogens would help to ensure 
incoming information in a multi-state outbreak is comparable. Undoubtedly, one of the most important tools needed for better investigations in the future, is a standardized traceback system that allows produce to be efficiently followed from the end consumer back to the grower for rapid identification of the source of contamination. In order to achieve this, regulations must be implemented to require a minimum amount of information be included in electronic records kept by all parties involved in the supply chain, including those businesses selling directly to the consumer such as restaurants and grocery stores. To allow for the degree of traceability demanded by the public, items need to be clearly marked and records need to be kept at the individual or package level so items retrieved from consumers can be traced back. As demonstrated in the recent Salmonella Saintpaul outbreak, information at the lot level for tomatoes is not useful if consumers buy one or two tomatoes from a chain grocery store that may have multiple lots available at any time; in order to trace produce commonly sold individually, each item needs to have identifying information and all records need to be kept in electronic format for quick access. In order to improve the speed of response for the next foodborne outbreak and minimize the number of people affected, these topics need to be addressed to ensure that current knowledge and technology are fully exploited.

While some of these concerns were obvious before the Salmonella Saintpaul outbreak, their importance has since become indisputable. For some of these, change will be difficult and require cooperative efforts from many sources; some may not have clear-cut answers. However, in order to increase the effectiveness of the food safety system, these issues must be addressed. Only by increasing financial resources, improving cooperation and information-sharing among stakeholders, evaluating current methodologies, and implementing new tools will the universal goal of improved food safety be achieved. 


\section{Conclusion}

This paper sought to answer the question: What factors most affected the difficulty experienced during the Salmonella Saintpaul outbreak and subsequent investigation, and are these factors representative of larger problems in the food safety system? While the Salmonella Saintpaul outbreak was unusual in many aspects and it would be foolhardy to make sweeping generalizations and reforms on the basis of one abnormal event, this investigation highlighted factors in need of improvement among all layers of government that must be addressed for our food safety system to prevent or minimize future outbreaks. Three factors that emerged included (1) delayed response due to discrepancies in available resources and expertise at state and local levels, (2) inadequate communication between agencies and stakeholders, and (3) poor traceability capabilities. Many other topics (e.g., increased resources for the FDA, risk-based inspections and testing, equal food safety standards for imported foods and the use of GAPs, and third party auditors) have come to the forefront in connection to the Salmonella Saintpaul outbreak; while the authors acknowledge the importance of these concepts, they are beyond the scope of this discussion.

The U.S. food safety system is, indeed, confronted by many formidable challenges. The emergence of new pathogens such as Escherichia coli O157:H7, the economic burden placed on the American public by repeated foodborne outbreaks, and the massive increase in produce imported from foreign countries with questionable (or nonexistent) food safety statutes demand an especially vigilant food safety system ${ }^{33}$. As the amount of fresh produce consumed by Americans continues to increase, lessons learned from the Salmonella Saintpaul outbreak need to be applied to the current food safety system to try and prevent similar situations. 
While several groups investigated whether errors may or may not have been made in the recent Salmonella Saintpaul outbreak, many people in multiple organizations at many different levels worked hard to identify the source of contamination and protect the American public. In one sense, the food safety system succeeded as the source of contamination was determined. However, the three factors responsible for much of the difficulty experienced in the Salmonella Saintpaul outbreak do, indeed, signal wider problems within the food safety system, and any legislative revision of the U.S. food safety system must address these factors. 


\section{References}

1. DeWaal CS, Plunkett DW. Building a modern food safety system: for FDA regulated foods. A CSPI white paper. Available at http://www.cspinet.org/new/pdf/fswhitepaper.pdf. Accessed on November 5, 2008.

2. The recent Salmonella outbreak: lessons learned and consequences in industry and public health: Hearing before the Subcommittee on Oversight and Investigations of the Committee on Energy and Commerce, $110^{\text {th }}$ Cong., $2^{\text {nd }}$ Sess. (2008) (testimony of Dr. Michael Taylor, research professor of health policy, The George Washington University).

3. Legal and technological capacity for full traceability in fresh produce: Hearing before the Subcommittee on Horticulture and Organic Agriculture of the House of Representatives Committee on Agriculture, $110^{\text {th }}$ Cong, $2^{\text {nd }}$ Sess (2008)(testimony of Dr. David Acheson, Associate Commissioner for Food Protection, FDA).

4. Legal and technological capacity for full traceability in fresh produce: Hearing before the Subcommittee on Horticulture and Organic Agriculture of the House of Representatives Committee on Agriculture, $110^{\text {th }}$ Cong, $2^{\text {nd }}$ Sess (2008)(testimony of Dr. Lonnie King, ZVED, CDC).

5. Bowling A. Research Methods in Health: Investigating Health and Health Services. Buckingham, England: Open University Press, 1997.

6. Smith D.F. and J. Phillips, ed. Food, Science, Policy and Regulation in the Twentieth Century. London, England;Routledge, 2000. 
7. The recent Salmonella outbreak: lessons learned and consequences in industry and public health: Hearing before the Subcommittee on Oversight and Investigations of the Committee on Energy and Commerce, $110^{\text {th }}$ Cong., $2^{\text {nd }}$ Sess. (2008) (testimony of the Honorable A.G. Kawamura, secretary, Dept of Food and Ag).

8. Centers for Disease Control and Prevention. Outbreak of Salmonella Saintpaul infection associated with multiple raw produce items-United States, 2008. MMWR. $2008 ; 57 ; 929-934$.

9. Food Safety: Hearing before the Subcommittee on Agriculture, Rural Development, Food and Drug Administration, and Related Agencies of the Appropriations Committee, $110^{\text {th }}$ Cong, $2^{\text {nd }}$ Sess (2008)(testimony of Dr. David Acheson, Associate Commissioner for Food Protection, FDA).

10. Centers for Disease Control and Prevention. Multistate outbreak of Salmonella serotype Saintpaul infections - clusters related to restaurants and events, preliminary analysis, July 11, 2008. Available at: http://www.cdc.gov/salmonella/saintpaul/.

11. Centers for Disease Control and Prevention. Multistate outbreak of Salmonella serotype Saintpaul infections-case-control study 1, preliminary analysis, July 11, 2008. Available at: http://www.cdc.gov/salmonella/saintpaul/.

12. Centers for Disease Control and Prevention. Multistate outbreak of Salmonella serotype Saintpaul infections—case-control study 2, preliminary analysis, July 11, 2008.

Available at: http://www.cdc.gov/salmonella/saintpaul/. 
13. Centers for Disease Control and Prevention. Preliminary FoodNet data on the incidence of infection with pathogens transmitted commonly through food—-10 states, United States 2005. MMWR. 2006;55;392-395.

14. The recent Salmonella outbreak: lessons learned and consequences in industry and public health: Hearing before the Subcommittee on Oversight and Investigations of the Committee on Energy and Commerce, $110^{\text {th }}$ Cong., $2^{\text {nd }}$ Sess. (2008) (testimony of Dr. Kirk Smith, supervisor of foodborne, vectorborne, and zoonotic disease unit, Dept of Health, State of MN).

15. Legal and technological capacity for full traceability in fresh produce: Hearing before the Subcommittee on Horticulture and Organic Agriculture of the House of Representatives Committee on Agriculture, $110^{\text {th }}$ Cong, $2^{\text {nd }}$ Sess (2008)(testimony of Dr. Michael Osterholm, Dr.Craig Hedberg, Dr. John Besser, School of Pub Health, U of $\mathrm{MN})$.

16. The recent Salmonella outbreak: lessons learned and consequences in industry and public health: Hearing before the Subcommittee on Oversight and Investigations of the Committee on Energy and Commerce, $110^{\text {th }}$ Cong., $2^{\text {nd }}$ Sess. (2008) (testimony of Dr. Timothy Jones, state epidemiologist, state of TN).

17. Food Safety: Hearing before the Subcommittee on Agriculture, Rural Development, Food and Drug Administration, and Related Agencies of the Appropriations Committee, $110^{\text {th }}$ Cong, $2^{\text {nd }}$ Sess (2008)(testimony of Dr. Michael Taylor, research professor of health policy, The George Washington University). 
18. The recent Salmonella outbreak: lessons learned and consequences in industry and public health: Hearing before the Subcommittee on Oversight and Investigations of the Committee on Energy and Commerce, $110^{\text {th }}$ Cong., $2^{\text {nd }}$ Sess. (2008) (testimony of the Honorable Charles Bronson, commissioner of agriculture, Dept. of Ag and Consumer Services, State of FL).

19. Washington Watch. S.3358, the improving food-borne illness surveillance and response act of 2008. Available at: http://www.washingtonwatch.com/bills/show /110_SN_3358.html. Accessed January 3, 2009.

20. The recent Salmonella outbreak: lessons learned and consequences in industry and public health: Hearing before the Subcommittee on Oversight and Investigations of the Committee on Energy and Commerce, $110^{\text {th }}$ Cong., $2^{\text {nd }}$ Sess. (2008) (testimony of Mr. Reginald Brown, executive vice president, FL Tomato Growers Exchange).

21. The recent Salmonella outbreak: lessons learned and consequences in industry and public health: Hearing before the Subcommittee on Oversight and Investigations of the Committee on Energy and Commerce, $110^{\text {th }}$ Cong., $2^{\text {nd }}$ Sess. (2008) (testimony of Dr. Donna Garren, vice president, Natl Restaurant Assoc).

22. The recent Salmonella outbreak: lessons learned and consequences in industry and public health: Hearing before the Subcommittee on Oversight and Investigations of the Committee on Energy and Commerce, $110^{\text {th }}$ Cong., $2^{\text {nd }}$ Sess. (2008) (testimony of Mr. Henry Giclas, vice president, Western Growers Assoc).

23. Legal and technological capacity for full traceability in fresh produce: Hearing before the Subcommittee on Horticulture and Organic Agriculture of the House of 
Representatives Committee on Agriculture, $110^{\text {th }}$ Cong, $2^{\text {nd }}$ Sess (2008)(testimony of Dr. James Gorny, executive director, Postharvest Tech Res \& Info Ctr).

24. Legal and technological capacity for full traceability in fresh produce: Hearing before the Subcommittee on Horticulture and Organic Agriculture of the House of Representatives Committee on Agriculture, $110^{\text {th }}$ Cong, $2^{\text {nd }}$ Sess (2008)(testimony of Mr. Henry Giclas, vice president, Western Growers Assoc).

25. World Health Organization. Definitions or risk analysis terms related to food safety. Available at: http:/www.who.int/foodsafety/publications/micro /riskanalysis_definitions/en/. Accessed January 3, 2009.

26. Produce Safety Project. Breakdown: lessons to be learned from the 2008 Salmonella Saintpaul outbreak. Available at http://www.producesafetyproject.org/admin/assets /files/0016.pdf. Accessed November 29, 2008.

27. World Health Organization. Effective media communication during public health emergencies: a WHO field guide. Available at: http://www.who.int/csr/resources/ publications/WHO\%20MEDIA\%20FIELD\%20GUIDE.pdf. Accessed on March 30, 2009.

28. World Health Organization, Food and Agriculture Organization of the United Nations. Food safety risk analysis: a guide for national food safety authorities. FAO Food Nutr Pap. 2006:87:1-102.

29. Department of Health and Human Services, Office of Inspector General. Traceability in the food supply chain. Available at: http://www.oig.hhs.gov/oei/reports/oei-02-0600210.pdf. Accessed on April 02, 2009. 
30. Legal and technological capacity for full traceability in fresh produce: Hearing before the Subcommittee on Horticulture and Organic Agriculture of the House of Representatives Committee on Agriculture, $110^{\text {th }}$ Cong, $2^{\text {nd }}$ Sess (2008)(testimony of Ms. Jean Halloran, director, Consumers Union).

31. The recent Salmonella outbreak: lessons learned and consequences in industry and public health: Hearing before the Subcommittee on Oversight and Investigations of the Committee on Energy and Commerce, $110^{\text {th }}$ Cong., $2^{\text {nd }}$ Sess. (2008) (testimony of Mr. Ed Beckman, president, CA Tomato Farmers).

32. The recent Salmonella outbreak: lessons learned and consequences in industry and public health: Hearing before the Subcommittee on Oversight and Investigations of the Committee on Energy and Commerce, $110^{\text {th }}$ Cong., $2^{\text {nd }}$ Sess. (2008) (testimony of Mr. Parker Booth, president, Ace Tomato Co).

33. The recent Salmonella outbreak: lessons learned and consequences in industry and public health: Hearing before the Subcommittee on Oversight and Investigations of the Committee on Energy and Commerce, $110^{\text {th }}$ Cong., $2^{\text {nd }}$ Sess. (2008) (testimony of Mr. William Hubbard, senior advisor, Coalition for a Stronger FDA).

34. Legal and technological capacity for full traceability in fresh produce: Hearing before the Subcommittee on Horticulture and Organic Agriculture of the House of Representatives Committee on Agriculture, $110^{\text {th }}$ Cong, $2^{\text {nd }}$ Sess (2008)(testimony of Mr. Bryan Silbermann, president, PMA).

35. Legal and technological capacity for full traceability in fresh produce: Hearing before the Subcommittee on Horticulture and Organic Agriculture of the House of 
Representatives Committee on Agriculture, $110^{\text {th }}$ Cong, $2^{\text {nd }}$ Sess (2008)(testimony of the Honorable Diana DeGette, $1^{\text {st }}$ Congressional District of CO).

36. Legal and technological capacity for full traceability in fresh produce: Hearing before the Subcommittee on Horticulture and Organic Agriculture of the House of Representatives Committee on Agriculture, $110^{\text {th }}$ Cong, $2^{\text {nd }}$ Sess (2008)(testimony of the Honorable Adam Putnam, $12^{\text {th }}$ Congressional District of FL).

37. Food Safety: Hearing before the Subcommittee on Agriculture, Rural Development, Food and Drug Administration, and Related Agencies of the Appropriations Committee, $110^{\text {th }}$ Cong, $2^{\text {nd }}$ Sess (2008)(testimony of Dr. Jeffrey Levi, exec director, Trust for America's Health). 
Table 1 Sources and types of publically available data used to investigate factors potentially contributing to the complexity of the 2008 Salmonella Saintpaul outbreak and subsequent investigation.

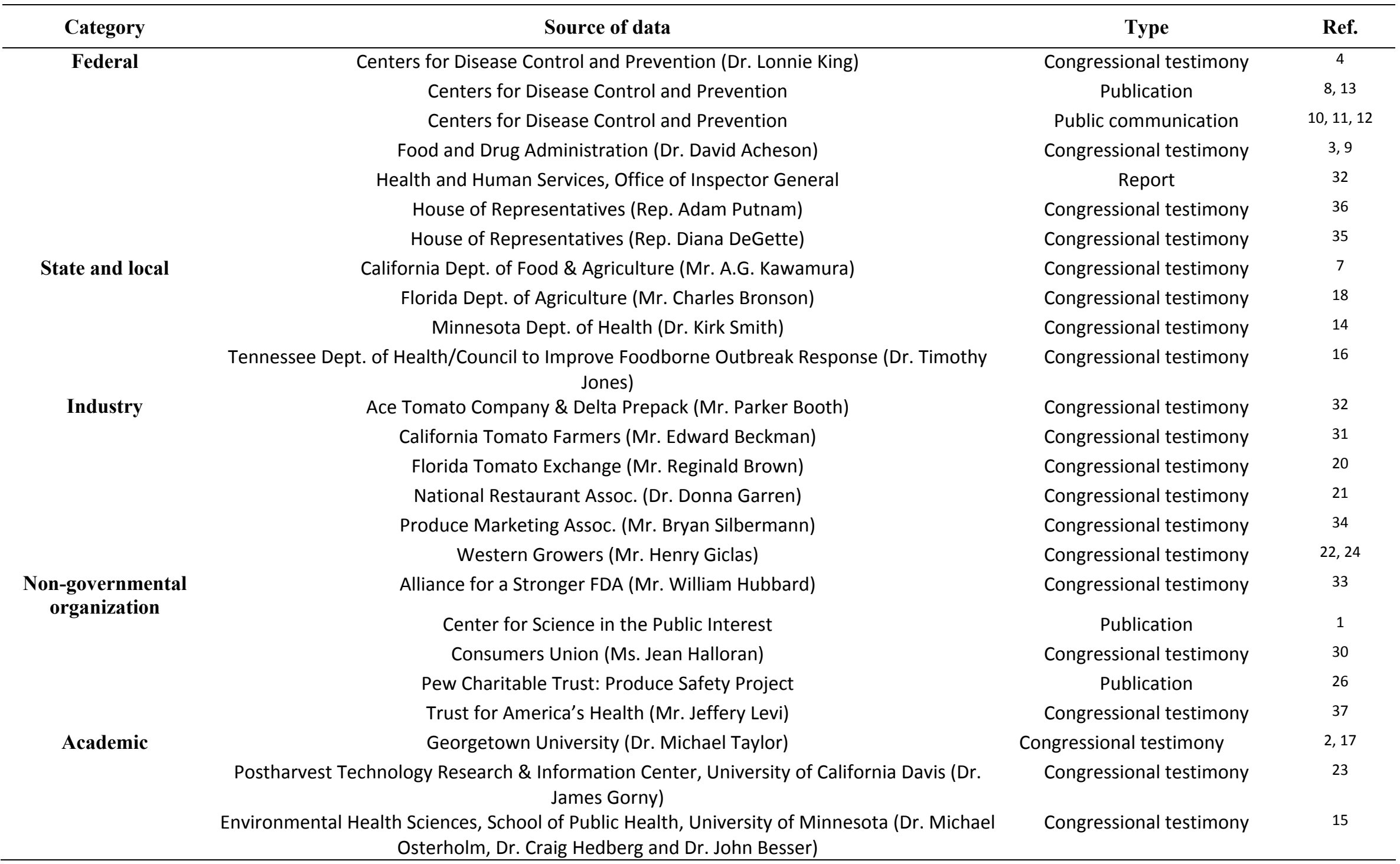


Table 2 Timeline of events associated with the 2008 Salmonella Saintpaul outbreak in produce. ${ }^{6,10-12}$

\begin{tabular}{ll}
\hline $\begin{array}{l}\text { Date } \\
\text { May 22 }\end{array}$ & New Mexico Dept. of Health notifies CDC of 4 confirmed cases of $S$. Saintpaul \\
May 23 & Texas and Colorado report additional $S$. Saintpaul cases with matching PFGE patterns. \\
& Multistate investigation led by New Mexico Dept. of Health begins. \\
May 31 & $\begin{array}{l}\text { New Mexico Dept. of Health announces link between } S . \text { Saintpaul and red plum, red } \\
\text { Roma and red round tomatoes. }\end{array}$
\end{tabular}

June 1 FDA begins traceback for suspected tomatoes.

June 3 CDC announces a warning for the consumption of red plum, red Roma or red round tomatoes by high-risk individuals in New Mexico or Texas.

$\mathrm{CDC}$ is asked to assume a coordinating role in the multistate outbreak investigation.

June 7 FDA issues a consumer advisory against consumption of red plum, red Roma or red round tomatoes.

June 18 Texas issues invitation for an Epi-Aid from CDC to investigate outbreaks associated with Mexican style restaurants.

June 30- Case-control study in Texas implicates salsa made with jalapeño peppers and canned July7 tomatoes.

July 1 Minnesota reports outbreak of $S$. Saintpaul associated with jalapeño pepper consumption.

July 9 CDC announces a consumer warning for the consumption of jalapeño peppers by high risk individuals.

July 17 FDA lifts consumer advisory against red plum, red Roma and red round tomatoes currently on the market.

July 21 FDA and CDC announce outbreak strain has been isolated from a jalapeño pepper sample in Texas.

FDA and CDC issue warning against consumption of fresh jalapeño peppers.

Late July Contaminated jalapeño pepper sample is traced back to a suspected farm (Farm A) in Mexico which also grows serrano peppers and Roma tomatoes.

FDA finds matching isolates from a serrano pepper and water sediment samples on a neighboring farm (Farm B) in Mexico.

Farm A and Farm B share a common packing facility in Mexico.

August 28 CDC updates website to reflect the apparent end of the outbreak. 